\title{
Blood-spinal cord barrier breakdown and pericyte reductions in amyotrophic lateral sclerosis
}

\author{
Ethan A. Winkler · Jesse D. Sengillo · John S. Sullivan • \\ Jenny S. Henkel $\cdot$ Stanley H. Appel $\cdot$ Berislav V. Zlokovic
}

Received: 25 July 2012/Revised: 21 August 2012/ Accepted: 23 August 2012/Published online: 1 September 2012

(C) The Author(s) 2012. This article is published with open access at Springerlink.com

\begin{abstract}
The blood-brain barrier and blood-spinal cord barrier (BSCB) limit the entry of plasma components and erythrocytes into the central nervous system (CNS). Pericytes play a key role in maintaining blood-CNS barriers. The BSCB is damaged in patients with amyotrophic lateral sclerosis (ALS). Moreover, transgenic ALS rodents and pericyte-deficient mice develop BSCB disruption with erythrocyte extravasation preceding motor neuron dysfunction. Here, we studied whether BSCB disruption with erythrocyte extravasation and pericyte loss are present in human ALS. We show that 11 of 11 cervical cords from ALS patients, but 0 of 5 non-neurodegenerative disorders controls, possess perivascular deposits of erythrocytederived hemoglobin and hemosiderin typically $10-50 \mu \mathrm{m}$ in diameter suggestive of erythrocyte extravasation. Immunostaining for CD235a, a specific marker for erythrocytes, confirmed sporadic erythrocyte extravasation in ALS, but not controls. Quantitative analysis revealed a 3.1-fold increase in perivascular hemoglobin deposits in ALS compared to controls showing hemoglobin confined within the vascular lumen, which correlated with 2.5 -fold increase in hemosiderin deposits $(r=0.82, p<0.01)$.
\end{abstract}

E. A. Winkler and J. D. Sengillo contributed equally to this work.

E. A. Winkler · J. D. Sengillo · J. S. Sullivan .

B. V. Zlokovic $(\square)$

Center for Neurodegeneration and Regeneration,

Zilkha Neurogenetic Institute, University of Southern California,

Room: 101, 1501 San Pablo Street, Los Angeles,

CA 90089, USA

e-mail: zlokovic@usc.edu

J. S. Henkel · S. H. Appel

Department of Neurology, Methodist Neurological Institute,

The Methodist Hospital Research Institute,

The Methodist Hospital, Houston, TX, USA
Spinal cord parenchymal accumulation of plasma-derived immunoglobulin G, fibrin and thrombin was demonstrated in ALS, but not controls. Immunostaining for plateletderived growth factor receptor- $\beta$, a specific marker for CNS pericytes, indicated a $54 \%(p<0.01)$ reduction in pericyte number in ALS patients compared to controls. Pericyte reduction correlated negatively with the magnitude of BSCB damage as determined by hemoglobin abundance $(r=-0.75, p<0.01)$. Thus, the BSCB disruption with erythrocyte extravasation and pericyte reductions is present in ALS. Whether similar findings occur in motor cortex and affected brainstem motor nuclei remain to be seen.

Keywords Amyotrophic lateral sclerosis - Pericytes . Vascular injury · Blood-brain barrier .

Blood-spinal cord barrier

\section{Introduction}

Amyotrophic lateral sclerosis (ALS) is the most common motor neuron disorder with an incidence of approximately 2-3 cases annually per 100,000 people [18, 37, 43, 69]. Approximately $90 \%$ of cases are sporadic and of unknown molecular etiology. The remaining $10 \%$ of cases are inherited as autosomal dominant mutations in as many as 12 genes, including those encoding for superoxide dismutase 1 (SOD1), TAR DNA binding protein (TDP-43), fusion in sarcoma (FUS), angiogenin (ANG) and optineurin $(O P T N)[1,22]$, and an expanded hexanucleotide repeat of GGGGCC in a noncoding region of the C9Orf72 gene $[15,55]$. Motor neuron injury and loss appear to result from the interaction of pathological processes arising from within neurons and neighboring non-neuronal cells. Noncell autonomous sources of motor neuron injury have been 
identified in transgenic ALS mouse models [5, 9, 12, 34, 65] and human neuronal co-cultures [30], and have largely focused on glial cell populations [52].

In contrast to leaky systemic capillaries [44], the bloodbrain barrier (BBB) and blood-spinal cord barrier (BSCB) prevent the entry of toxic circulating molecules, erythrocytes and leukocytes into the central nervous system (CNS) $[62,70,71]$. The BBB/BSCB is damaged in ALS subjects as shown through analysis of albumin and other serum-derived proteins in the cerebrospinal fluid (CSF) and measurements of albumin CSF/serum quotients [2, 3, 10, 29, 40, 45, 53, 57], as well as postmortem pathologic analyses of spinal cord or motor cortex tissue [17, 20, 21, 31, 32, 58]. Consistent with findings in humans, transgenic rodents expressing mutant isoforms of human SOD1 develop a spontaneous BSCB breakdown [24-26, 46, 48, 66, 67]. In SOD1 transgenic mice, BSCB breakdown causing extravasation of erythrocytes precedes motor symptoms and neuronal loss [46, 66, 67]. Recent studies in transgenic rodents with dysfunctional signaling in pericytes have demonstrated that pericytes play a key role in maintaining the integrity of the BBB and BSCB [4, 6, 7, 14, 63]. For example, mice with deficient platelet-derived growth factor receptor- $\beta(P d g f r \beta)$ signaling in pericytes resulting in pericyte loss develop chronic BBB and/or BSCB disruption with accumulation of plasma proteins and erythrocyte extravasation preceding neuronal injury $[6,63]$.

In the present study, we utilized high resolution histopathologic analyses to determine whether BSCB disruption in humans with ALS results in extravasation of erythrocytes in motor neuron dense regions of the spinal cord, and whether BSCB disruption in human ALS is associated with a reduction in the pericyte population. We show not only that capillary leakage of erythrocytes and plasma proteins is present in ALS, but also that vascular rupture coincides with reductions in capillary pericyte populations in human ALS spinal cord tissue specimens. These findings raise a number of questions regarding the significance and/or contributory role of vascular dysfunction in ALS pathogenesis.

\section{Materials and methods}

\section{Human subjects}

Written consent was obtained and approved by The Methodist Hospital from all human subjects utilized in this study prior to death. The postmortem interval ranged between 5 and $16 \mathrm{~h}$ for all tissue samples. Postmortem cervical spinal cord tissue samples were obtained from subjects with a definite diagnosis of ALS according to the WFN El Escorial/Airlie criteria. Following cervical spinal cord isolation, tissue samples were immediately snap frozen and stored at
$-80{ }^{\circ} \mathrm{C}$, unless otherwise indicated. In total, tissue samples from eight subjects with sporadic sALS, three subjects with familial (fALS) and five non-neurodegenerative disease controls (NNDC) were utilized for all studies (see Table 1 for details). The cause of death in all ALS patients was respiratory failure, whereas the cause of death in NNDC cases was either cardiac failure or respiratory failure.

\section{Perivascular hemosiderin deposits}

To analyze perivascular Prussian blue-positive hemosiderin deposits, tissues were cryosectioned at a thickness of $14 \mu \mathrm{m}$, fixed with immersion in ice cold acetone and stored at $-20{ }^{\circ} \mathrm{C}$. Sections were then rehydrated in PBS and blocked in $10 \%$ normal swine serum. Sections were then incubated in goat anti-human podocalyxin (1:100, R\&D systems, Minneapolis, MN, USA). Sections were then incubated with horseradish peroxidase (HRP)-conjugated rabbit anti-goat secondary antibody (Bio-Rad, Hercules, CA, USA). Podocalyxin positive vessels were subsequently visualized utilizing 3-3'-diaminobenzidine (DAB) peroxidase substrate kit (Vector Laboratories, Burlingame, CA, USA). Prussian blue staining was then performed as we previously described $[6,66,67]$. Briefly, sections were incubated in $5 \%$ potassium ferrocyanide and $5 \%$ hydrochloric acid solution (diluted 1:1) for $30 \mathrm{~min}$ at $37^{\circ} \mathrm{C}$. Sections were then rinsed in water, mounted in Cytoseal XYL mounting media (Thermo Scientific, Waltham, MA, USA) and coverslipped.

To quantify perivascular Prussian-blue positive hemosiderin deposits, a minimum of five $1.27 \times 0.95 \mathrm{~mm}$ images confined to the anterior horn gray matter were randomly taken using a Leica DMI6000 inverted epifluorescent microscope (Leica Instruments, Nussloch, Germany) per section. Six non-adjacent tissue sections $(\sim 100 \mu \mathrm{m}$ apart) were analyzed per subject. Perivascular Prussian-blue positive hemosiderin deposits were manually counted and expressed per $\mathrm{mm}^{2}$ spinal cord.

Hematoxylin and eosin staining

Following spinal cord isolation, tissue samples were fixed in formalin and embedded in paraffin. Embedded tissue

Table 1 Demographic and clinical features of human subjects

\begin{tabular}{llll}
\hline & NNDC $(n=5)$ & sALS $(n=8)$ & fALS $(n=3)$ \\
\hline $\begin{array}{l}\text { Gender } \\
(\mathrm{M} / \mathrm{F})\end{array}$ & $3 / 2$ & $5 / 3$ & $2 / 1$ \\
$\begin{array}{l}\text { Age of diagnosis } \\
\text { (mean } \pm \mathrm{SD})\end{array}$ & - & $56.5 \pm 13.3$ & $56.4 \pm 3.0$ \\
$\begin{array}{l}\text { Disease duration } \\
\text { (mean } \pm \mathrm{SD})\end{array}$ & - & $4.6 \pm 4.7$ & $3.1 \pm 2.4$ \\
$\begin{array}{l}\text { Age of death } \\
(\text { mean } \pm \mathrm{SD})\end{array}$ & $61.2 \pm 10.0$ & $60.7 \pm 12.5$ & $59.5 \pm 1.8$ \\
\hline
\end{tabular}


was sectioned using a Leica RM2125 microtome at a thickness of $5 \mu \mathrm{m}$. Sections were deparaffinized with xylene and rehydrated to distilled water with serial ethanol washes. Hematoxylin and eosin staining was then performed as described by the manufacturer (FD NeuroTechnologies, Columbia, MD). Sections were subsequently coverslipped using Cytoseal XYL mounting media (Thermo Scientific) and imaged using a Leica DMI6000 inverted epifluorescent microscope (Leica Instruments).

\section{Immunofluorescent analysis}

Snap frozen cervical spinal cords were embedded in optimal cutting temperature (OCT) compound (Tissue-Tek, Torrance, CA, USA). Embedded tissues were cryosectioned at a thickness of $14 \mu \mathrm{m}$, fixed with immersion in ice cold acetone and stored at $-20{ }^{\circ} \mathrm{C}$. Sections were rehydrated in phosphate buffered saline (PBS) and blocked in $10 \%$ normal swine serum (Vector Laboratories, Burlingame, CA, USA) for $1 \mathrm{~h}$ at room temperature. Sections were then incubated overnight at $4{ }^{\circ} \mathrm{C}$ in the following primary antibodies: goat anti-platelet derived growth factor $\beta$ (PDGFR $\beta)(10 \mu \mathrm{g} / \mathrm{mL}, \mathrm{R} \& \mathrm{D}$ systems), goat anti-hemoglobin ( $10 \mu \mathrm{g} / \mathrm{ml}, \mathrm{R} \& \mathrm{D}$ systems $)$, mouse anti-glycophorin A (CD235a) (1:100, Dako, Carpinteria, CA, USA), rabbit anti-fibrinogen (1:100, Dako), goat anti-thrombin (1:50, Santa Cruz Biotechnology, Santa Cruz, CA, USA) and mouse anti-neuronal specific antigen A60 (NeuN) (EMD Millipore, Billerica, MA, USA). To visualize pericytes, sections were incubated in bovine anti-goat Cy3 (Jackson ImmunoResearch Laboratories, Inc., West Grove, PA, USA) diluted 1:100 to detect PDGFR $\beta$. To detect erythrocytederived products, sections were incubated in bovine anti-goat Cy3 (Jackson Laboratories) and donkey-anti rabbit Alexa Fluor 488 (Jackson Laboratories) to detect hemoglobin and CD235a, respectively. To detect plasma proteins, sections were incubated in bovine anti-goat Cy3 (Jackson Laboratories) and donkey-anti rabbit Alexa Fluor 488 (Jackson Laboratories) to detect thrombin and fibrin, respectively. To visualize neurons, sections were incubated in donkey anti-mouse Alexa Fluor 488 (Jackson Laboratories) to visualize NeuN-positive cells. To visualize endothelial cells, sections were incubated in fluorescein labeled Ulex Europaeus Agglutinin I lectin (UEA-1) (Vector Laboratories) or biotinylated labeled UEA-1 (Vector Laboratories) followed by incubation in DyLight 649 conjugated streptavidin (Vector Laboratories). Following immunodetection, sections were incubated in $1 \%$ Sudan Black B (Sigma Aldrich, St. Louis, MO, USA) diluted in $70 \%$ ethanol for $10 \mathrm{~min}$ at room temperature.

Tissue sections were mounted with fluorescent mounting media (Dako) and coverslipped. All slides were scanned with a custom built Zeiss 510 meta confocal laser scanning microscope with a Zeiss Apochromat $25 \times / 0.8$ NA water immersion objective (Car Zeiss Microimaging Inc.,
Thornwood, NY, USA). A $488 \mathrm{~nm}$ argon laser was used to excite Alexa Fluor 488 and fluorescein and the emission was collected through a 500-550 nm band pass (bp) filter. A $543 \mathrm{~nm}$ HeNe laser was used to excite Cy3 and the emission was collected through a $560-615 \mathrm{~nm}$ bp filter. A $633 \mathrm{~nm}$ HeNe laser was used to excite DyLight 649 and the emission was collected through a $650-700 \mathrm{~nm}$ bp filter.

Image analysis

All image analyses were conducted utilizing NIH ImageJ software. For all analyses, a field size of $420 \times 420 \mu \mathrm{m}$ was utilized and 10-12 $\mu \mathrm{m}$ maximum projection $\mathrm{z}$-stack images were reconstructed. For all studies, five randomly selected fields confined within the anterior horn gray matter per section from six non-adjacent sections $(\sim 100 \mu \mathrm{m}$ apart) were analyzed from each tissue specimen. For pericyte coverage analysis, PDGFR $\beta$-positive surface area was determined by the ImageJ Area measurement tool and divided by the lectinpositive capillary surface area as we previously described [6, 61, 63]. Quantification of extravascular hemoglobin deposits were performed as we previously described for plasma proteins with several modifications [6, 66, 67]. Intravascular hemoglobin-positive immunofluorescent signal (hemoglobinpositive staining which co-localized with lectin positive capillaries) was subtracted from the z-stack images utilizing the ImageJ co-localization function. Following subtraction, the remaining extravascular hemoglobin-positive immunofluorescent signal was subjected to threshold processing and quantified using the ImageJ Integrated Density analysis.

For all studies of NNDC and ALS specimens, the same laser settings were utilized (i.e., laser power, amplifier gain and offset, scan speed, optical bandwidth filters, the size of z-stacks), and any variability in background was accounted for utilizing post-image thresholding. To avoid bias, a blinded investigator analyzed all images.

Statistical analysis

All data were analyzed using Student's $t$ test to analyze differences between ALS and NNDC groups. Correlations were determined using Pearson's correlation analysis. A $p$ value $<0.05$ was considered statistically significant in all studies. All values expressed as mean \pm standard error of the mean (SEM) unless otherwise indicated.

\section{Results}

BSCB breakdown in human ALS

Confocal microscopy analysis of the spinal cervical cord anterior horn gray matter detected multiple extravascular 

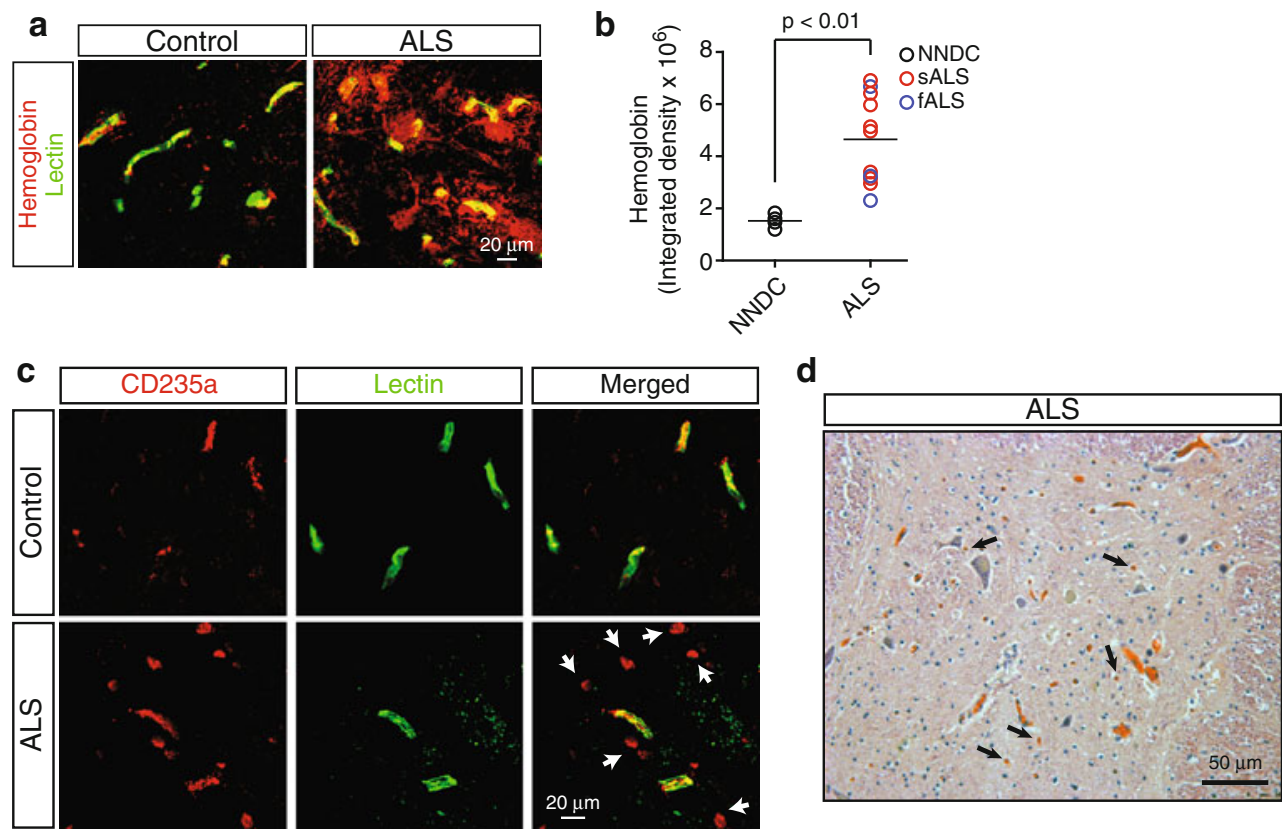

Fig. 1 Extravascular deposition of erythrocyte-derived hemoglobin and erythrocyte extravasation in the spinal cord of ALS subjects. a Confocal microscopy analysis of erythrocyte-derived hemoglobin (red) and lectin-positive capillaries (green) in NNDC and sporadic ALS cervical spinal cord anterior horn. b Quantification of extravascular hemoglobin deposits in the cervical spinal cord anterior horn. Mean \pm SEM, $n=5$ NNDC, eight sporadic (sALS) and three

deposits of erythrocyte-derived hemoglobin outside the vascular lumen as indicated by lectin-positive capillary profiles (Fig. 1a). Quantitative analysis revealed a 3.1-fold increase in extravascular hemoglobin deposits in ALS compared to NNDC (controls) showing non-subtracted background levels of intravascular hemoglobin, as indicated by staining with endothelial cell-specific lectin (mean hemoglobin (arbitrary units): ALS, 4,647,513 \pm 509,666; $n=11$ cases; NNDC, $1,525,775 \pm 132,292, n=5$ cases; for each case six sections and five randomly selected fields per section were analyzed) (Fig. 1b). A similar pattern of extravascular hemoglobin staining was observed in familial (fALS) cases. c Confocal microscopy analysis of CD235apositive erythrocytes ( $\mathrm{red}$ ) and lectin-positive capillaries (green) in a NNDC control and sporadic ALS cervical spinal cord anterior horn. d Extravasation of erythrocytes in ALS spinal cord anterior horn demonstrated by hematoxylin and eosin staining. In $\mathbf{c}$ and $\mathbf{d}$, Arrows denote extravasated erythrocytes in ALS sample

sporadic and familial ALS tissue specimens, but not NNDCs, irrespective of acetone or paraformaldehyde fixation. Simultaneous immunostaining for CD235a, a specific marker for erythrocytes $[11,19,47]$ and endothelial cell-specific lectin indicated the presence of sporadic CD235a-positive erythrocytes outside the spinal cord capillaries in ALS specimens, but not controls, as illustrated in Fig. 1c. Extravasation of erythrocytes in ALS has been confirmed by hematoxylin and eosin staining (Fig. 1d), in contrast to their strictly intravascular location in controls (not shown), as expected based on immunofluorescent staining (Fig. 1c).
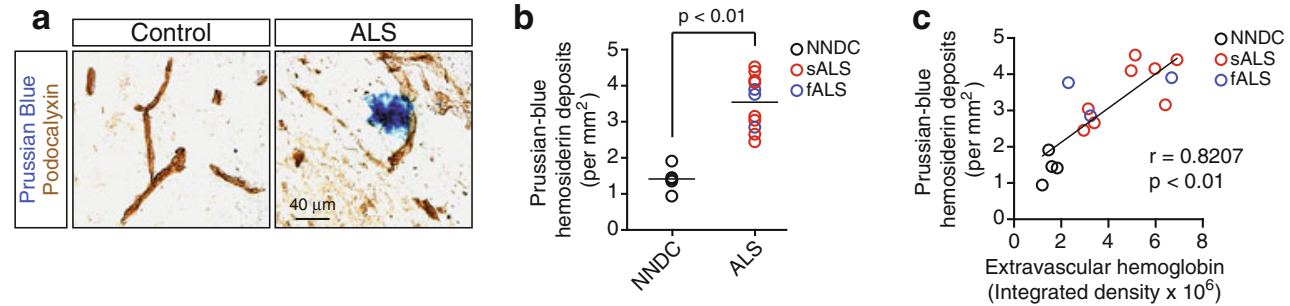

Fig. 2 Perivascular hemosiderin deposition in the spinal cord of ALS subjects. a Bright field microscopy analysis of Prussian blue-positive hemosiderin deposits (blue) and podocalyxin-postive capillaries (brown) in NNDC and sporadic ALS cervical spinal cord anterior horn. b Quantification of perivascular Prussian blue-positive hemosiderin deposits in the cervical spinal cord anterior horn.
Mean \pm SEM, $n=5$ NNDC, eight sporadic (sALS) and three familial (fALS) cases. c Positive correlation between perivascular hemosiderin deposits and extravascular hemoglobin deposition in cervical spinal cord anterior horn. Single data points derived from NNDC, sALS and fALS subjects. $r$ Pearson's coefficient 


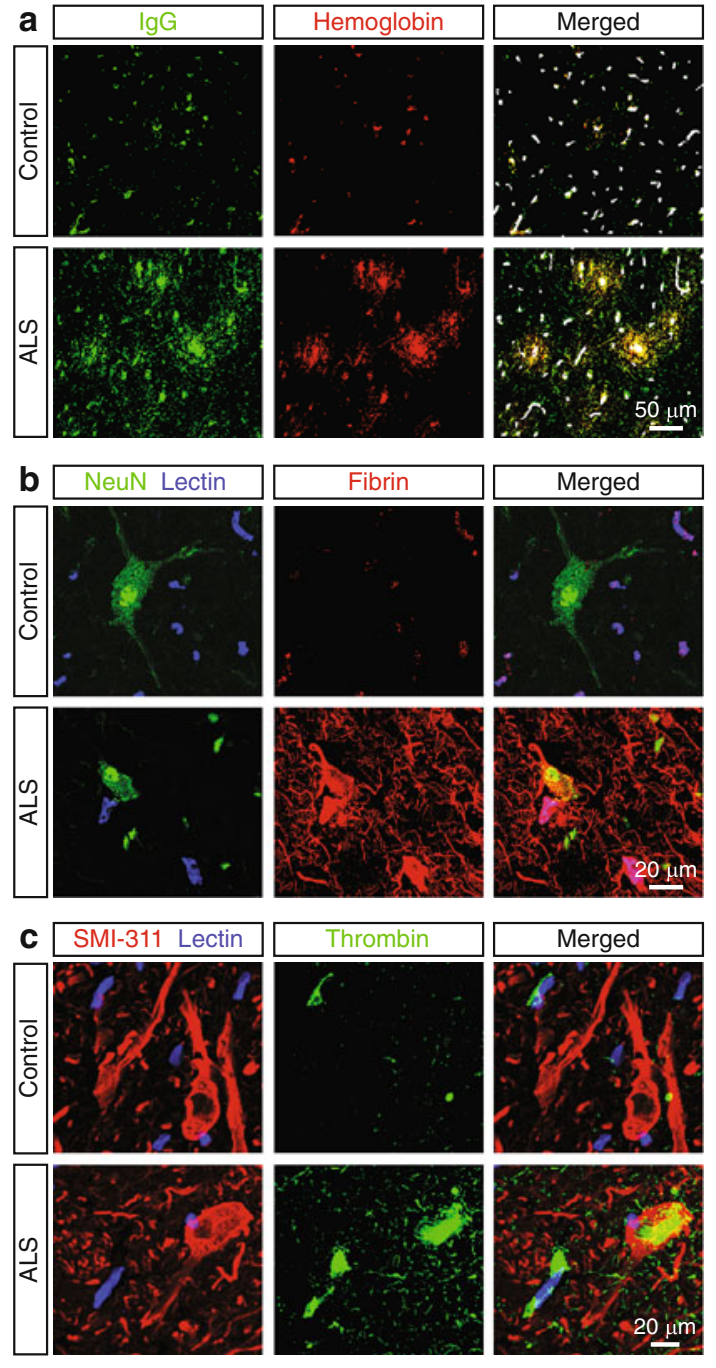

Fig. 3 Accumulation of plasma-derived proteins in the spinal cord of ALS subjects. a Confocal microscopy analysis of immunoglobulin $\mathrm{G}$ ( $\operatorname{IgG}$ ) (green) and hemoglobin (red) in NNDC and sporadic ALS cervical spinal cord anterior horn. Merged extravascular colocalization of IgG and hemoglobin, white lectin-positive capillary profiles. b Confocal microscopy analysis of plasma-derived fibrin (red), NeuN-positive neurons (green) and lectin-positive capillaries (blue) in NNDC and sporadic ALS cervical spinal cord anterior horn. c Confocal microscopy analysis of plasma-derived thrombin (green), SMI-311-positive neurons (green) and lectin-positive capillaries (blue) in NNDC and sporadic ALS cervical spinal cord anterior horn. Representative images are shown from 5 NNDC and 11 ALS cases

Bright field microscopy analysis of Prussian blue-positive hemosiderin deposits and podocalyxin-positive capillaries revealed perivascular hemosiderin deposits in ALS subjects, but not controls, typically $10-50 \mu \mathrm{m}$ in diameter predominately surrounding capillaries $(\leq 8 \mu \mathrm{m}$ in diameter $)$ (Fig. 2a). Quantification of Prussian blue-positive hemosiderin deposits detected approximately a 2.5 -fold increase in ALS when compared to NNDCs (mean number of hemosiderin deposits per $\mathrm{mm}^{2}$ : NNDS, $1.41 \pm 0.15, n=5$ cases; ALS, $3.54 \pm 0.22, n=11$ cases; for each case six sections and five randomly selected fields per section were analyzed) (Fig. 2b). In individual subjects, the magnitude of perivascular hemosiderosis positively correlated with the amount of extravascular erythrocyte-derived hemoglobin ( $r=0.8207, p<0.01$ ) (Fig. 2c), suggesting that lysis of extravasated erythrocytes contributes to the development of perivascular hemosiderin deposits.

Our data show significant perivascular accumulation of immunoglobulin $\mathrm{G}(\mathrm{IgG})$ that co-localized with hemoglobin deposits (Fig. 3a), suggestive of BSCB leakage as illustrated by lectin-positive capillaries. Plasma-derived fibrin (Fig. 3d) and thrombin (Fig. 3c) accumulations were also found in motor neuron dense regions in the cervical spinal cord anterior horn gray matter in sporadic ALS subjects, but not controls. Similar accumulates were found in familial ALS subjects. These data further illustrate that BSCB damage results in leakage of blood constituents in human ALS.

\section{Reduction of spinal cord pericyte population in ALS}

Using established methods $[6,7,61,63]$, we next determined the percentage of the capillary wall covered by PDGFR $\beta$-positive pericyte cell processes. As reported previously $[4,6,14,42,61,63]$, PDGFR $\beta$ was not expressed in astrocytes surrounding the vessel wall, as demonstrated by lack of PDGFR $\beta$ staining of astrocyte processes positive for glial fibrillar acidic protein, an astrocyte-specific marker. In total, 10 out of 11 subjects with ALS displayed reductions in pericyte coverage. Analysis revealed a statistically significant $19 \%$ reduction in mean PDGFR $\beta$-positive pericyte coverage of cervical anterior horn spinal cord capillaries in ALS subjects when compared to NNDCs (mean pericyte coverage: NNDC, $71 \pm 3 \%, n=5$ cases; ALS, $58 \pm 3 \% ; n=11$ cases; for each control and ALS case six sections per case and five randomly selected fields per section were analyzed) (Fig. 4a, b). In addition to reductions in pericyte coverage, 11 out of 11 subjects with ALS displayed reductions in the number of cervical anterior horn gray matter pericytes. Analysis showed approximately a $54 \%$ reduction in PDGFR $\beta$-positive pericyte number in ALS subjects when compared to NNDCs (mean pericyte number: NNDC, $750 \pm 78, n=5$ cases; ALS, $350 \pm 28, n=11$ cases; for each control and ALS case six sections per case and five randomly selected fields per section were analyzed) (Fig. 4c). In individual subjects, pericyte coverage correlated negatively with the magnitude of vessel rupture as measured by extravascular hemoglobin abundance $(r=-0.7462, p<0.01)$ (Fig. 4d). Collectively, these data suggest that reduced pericyte populations may contribute to 


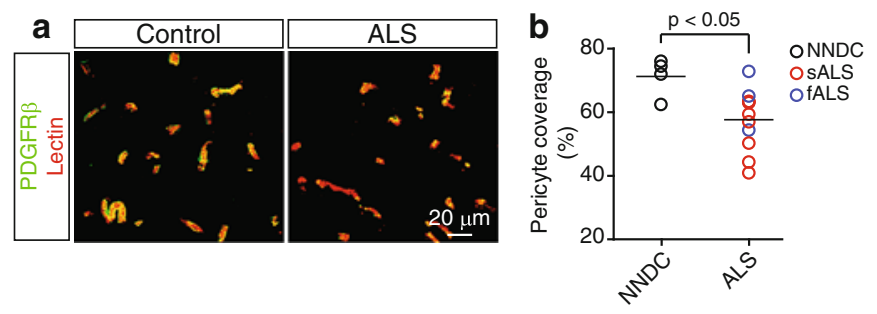

Fig. 4 Pericyte capillary reduction in ALS spinal cord correlates with magnitude of vascular disruption. a Representative confocal microscopy analysis of PDGFR $\beta$-positive pericytes (green) and lectinpositive capillaries (red) in NNDC and sporadic ALS cervical spinal cord anterior horn. b Quantification of PDGFR $\beta$-positive pericyte capillary coverage in cervical spinal cord anterior horn. Mean \pm SEM, $n=5$ NNDC, eight sporadic (sALS) and three familial (fALS)

microvascular fragility and BSCB breakdown in human ALS subjects.

\section{Discussion}

Our postmortem tissue analysis suggests that BSCB disruption in ALS patients leads to extravasation of erythrocytes in the spinal cord and subsequent accumulation of erythrocyte-derived hemoglobin and iron-containing hemosiderin, as well as extravasation of multiple plasmaderived proteins. We also show that BSCB breakdown in ALS subjects is associated with pericyte loss in motor neuron dense regions of the spinal cord, i.e., the cervical spinal cord anterior horn gray matter. The present study further supports the existence of alterations of the BSCB in ALS subjects. Past studies utilizing both CSF and tissue analyses have suggested possible BBB and/or BSCB disruption in a subset of human ALS subjects varying from 26 to $100 \%$ of cases depending on both the study and the parameter being analyzed (summarized in Table 2).

At a molecular level, transcriptional analysis has demonstrated that the tight junction proteins of the BSCB, i.e., zonula occludens-1 (ZO-1) and occludin, are reduced in sporadic and familial ALS cases in the lumbar spinal cord suggesting a potential mechanism for barrier disruption [31]. Elevations in matrix metalloproteinase-9 (MMP-9), an enzyme known to chronically degrade endothelial tight junctions [7], have also been detected in ALS serum samples [8, 16, 49] and postmortem brain and spinal cord specimens [41]. MMP-9 has been linked to degradation of the tight junction proteins and extracellular basement membrane matrix proteins at the BSCB of ALS patients by an independent study [46]. Our findings suggest that abnormalities may not be restricted to endothelial cells and that reductions in spinal cord capillary pericytes may also contribute to microvascular disruption in human subjects. Importantly, pericytes have been shown to promote
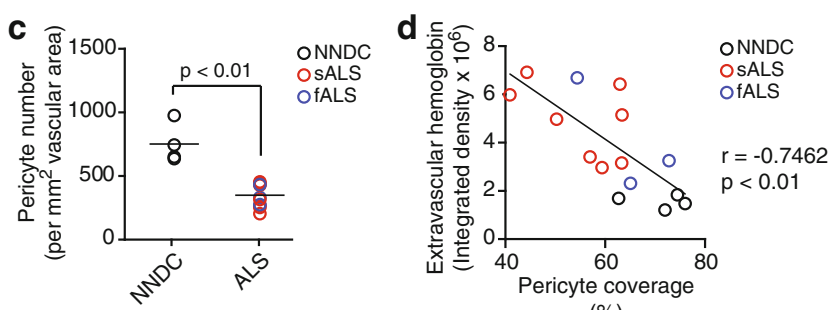

(\%)

cases. c Quantification of PDGFR $\beta$-positive pericyte cell number per $\mathrm{mm}^{2}$ vascular surface area in cervical spinal cord anterior horn. Mean \pm SEM, $n=5$ NNDC, eight sALS and three fALS. d Negative correlation between extent of extravascular hemoglobin and pericyte coverage in cervical spinal cord anterior horn. Single data points derived from NNDC, sALS and fALS subjects. $r$ Pearson's coefficient

endothelial tight junction protein expression, including $\mathrm{ZO}$ 1 and occludin [6], facilitate tight junctional alignment [14], and reduce endothelial vesicular uptake and transcytosis of circulating macromolecules [4]. Pericytes under pathologic conditions have been recently demonstrated to be an important source of secreted MMP-9 leading to degradation of both endothelial tight junctions and the basement membrane resulting in vascular fragility [7]. Whether a similar relationship exists in human ALS remains to be determined and should be addressed.

Unlike other neurodegenerative disorders with chronic CNS microhemorrhage, such as Alzheimer's disease [13, 27], the spinal cord erythrocyte extravasation described in ALS patients in this study was predominately confined to the capillary level. Following extravasation, erythrocytes lyse and liberate both membranous and cytoplasmic components including free hemoglobin [33, 51, 64]. Following lysis of extravasated erythrocytes, degradation of hemoglobin-derived heme within the CNS gives rise to carbon monoxide, bilirubin and iron [33, 64]. This results in local elevations of both free and protein-bound iron including the insoluble-iron storage protein hemosiderin [33, 64]. Hemosiderin deposits found in the present study were much smaller in size $(\sim 10-50 \mu \mathrm{m})$ than hemorrhages described at the arterial or arteriolar level and/or in Alzheimer's disease $(>100 \mu \mathrm{m})$ [13, 27, 56, 69]. Recent studies have demonstrated that circulating plasma penetrates five times faster than the erythrocyte core [56] and that the plasma protein diameter is typically 3 to 3.5 -fold larger than the erythrocyte core in CNS parenchyma following vascular disruption [39]. Similarly, we found that the diameter of distribution of extravasated plasma proteins, such as fibrin, was on average 3 to 4 -fold larger than that of hemoglobin. This likely reflects a more centrally localized erythrocyte core surrounded by peripheral plasma protein diffusion in human ALS spinal cord tissue.

Hemoglobin is toxic to motor neurons [54] and neural cells expressing different SOD1 mutants [67] in vitro 
Table 2 Prior studies suggestive of vascular disruption in sporadic and familial amyotrophic lateral sclerosis

\begin{tabular}{|c|c|c|c|}
\hline Parameter(s) & Key findings & $\begin{array}{l}\text { Proportion of subjects } \\
\text { with barrier dysfunction } \\
\text { (if applicable) }\end{array}$ & Reference \\
\hline \multicolumn{4}{|l|}{ Cerebrospinal fluid analyses } \\
\hline Total protein & Elevated CSF total protein & $26 \%(6 / 23)$ & [29] \\
\hline Total protein & Elevated CSF total protein & $n=14$ & {$[53]$} \\
\hline Plasma-derived protein & Increased albumin, $\operatorname{IgG}$ or total protein & $46 \%(41 / 90)$ & {$[40]$} \\
\hline Plasma-derived protein & Increased complement $\mathrm{C}_{3} \mathrm{c}$ in $\mathrm{CSF}$ & $n=13$ & [2] \\
\hline Plasma-derived protein & Elevated $\mathrm{CSF} /$ serum albumin ratio & $100 \%(4 / 4)$ & {$[57]$} \\
\hline Plasma-derived protein & Elevated CSF/serum albumin ratio & $46 \%(17 / 37)$ & [3] \\
\hline Plasma- derived protein & Elevated CSF/serum albumin ratio & $50 \%(15 / 30)$ & {$[45]$} \\
\hline Plasma-derived protein & Elevated $\mathrm{CSF} /$ serum albumin ratio & $28 \%(19 / 69)$ & {$[10]$} \\
\hline \multicolumn{4}{|c|}{ Postmortem spinal cord analyses } \\
\hline Plasma protein deposits & $\begin{array}{l}\text { Increased spinal cord and motor cortex deposition } \\
\text { of plasma-derived } \operatorname{IgG} \text { and } \mathrm{C}_{3}\end{array}$ & $\begin{array}{l}\text { Spinal cord: } 38 \%(6 / 16) \\
\text { Motor cortex: } 38 \%(5 / 13)\end{array}$ & {$[17]$} \\
\hline Plasma protein deposits & Increased neuronal uptake of plasma-derived $\mathrm{IgG}$ & $\begin{array}{l}\text { Spinal cord: } 87 \%(13 / 15) \\
\text { Motor cortex: } 55 \%(6 / 11)\end{array}$ & {$[20]$} \\
\hline Tight junction proteins & Decreased ZO-1 and occludin expression in ALS & $n=34$ & {$[31]$} \\
\hline Matrix metalloproteinase & $\begin{array}{l}\text { Increased MMP-9 activity in frontal and occipital cortices } \\
\text { and cervical, thoracic and lumbar spinal cord }\end{array}$ & $\begin{array}{l}\text { Cervical: } 100 \%(9 / 9) \\
\text { Thoracic and lumbar: } 78 \%(7 / 9) \\
\text { Frontal and occipital cortex: } 100 \%(9 / 9)\end{array}$ & [41] \\
\hline Inflammatory infiltrate & Increased number of spinal cord $\mathrm{T}$ cell lymphocytes & $100 \%(8 / 8)$ & {$[58]$} \\
\hline Inflammatory infiltrate & Increased number of spinal cord $\mathrm{T}$ cell lymphocytes & $70 \%(18 / 27)$ & {$[20]$} \\
\hline Inflammatory infiltrate & $\begin{array}{l}\text { Increased number of spinal cord dendritic cells } \\
\text { and transcripts }\end{array}$ & $100 \%(5 / 5)$ & {$[32]$} \\
\hline \multicolumn{4}{|l|}{ Serum analyses } \\
\hline Matrix metalloproteinase & Elevated MMP-9 levels in ALS serum samples & $\begin{array}{l}\text { MMP-9 Levels: } n=14 \\
\text { MMP-9 Activity: } 65 \%(9 / 14)\end{array}$ & [8] \\
\hline Matrix metalloproteinase & Elevated pro- and active-MMP-9 in ALS serum samples & $n=25$ & {$[16]$} \\
\hline Matrix metalloproteinase & $\begin{array}{l}\text { Elevated levels of MMP-2 and MMP-9 in ALS } \\
\text { serum samples }\end{array}$ & MMP-9 levels: 70 \% (21/30) & [49] \\
\hline
\end{tabular}

through iron-dependent oxidative injury. In mouse models of ALS [46, 66, 67] and in pericyte-deficient mice with disrupted PDGFR $\beta$ signaling in pericytes [63], BSCB disruption with erythrocyte extravasation and/or motor neuron accumulation of extravasated plasma-proteins such as thrombin and fibrin precedes motor neuron injury. Whether small foci of extravasated erythrocytes can contribute to motor neuron injury in the spinal cord of ALS patients, and whether extravasated proteins (e.g., fibrin, thrombin) localize on the surface or inside motor neurons in human ALS, as found in cortical and/or motor neurons in pericyte-deficient mice [4, 6, 63] or transgenic apolipoprotein E4-expressing mice [7], require future experimental investigation.

Perivascular hemosiderin deposits account for perivascular hypointensities of T2*-weighted MRI analysis utilized clinically for the detection of intracerebral microhemorrhage $[27,28,60]$. The small size of spinal cord hemosiderin deposits as described in the present study may pose a significant barrier to the sensitivity and specificity of conventional T2*-weighted MRI imaging pulse sequences in human subjects $[27,28,60,68]$. Therefore, MRI studies in ALS patients should be interpreted with caution [68]. For example, one brain MRI study failed to detect microhemorrhages that were $<100 \mu \mathrm{m}$ in diameter in a small number of ALS patients [59], possibly due to limited resolution of imaging [27, 60, 68]. Future studies are needed combining MRI and histopathologic analyses to better optimize pulse sequences for the detection of perivascular hemosiderin deposits in ALS patients, especially in the spinal cord, which has yet to be investigated. Whether ALS patients develop BBB disruption with erythrocyte extravasation, hemosiderin deposition, and/or pericyte reductions in motor cortex and affected brainstem motor nuclei remains to be seen.

Greater than $99 \%$ of circulating iron is bound to hemoglobin [23] and, therefore likely contributes to 
previously reported elevations in CNS iron in human ALS $[35,36,38,50]$. In addition, we demonstrate accumulation of plasma-derived proteins including $\mathrm{IgG}$, fibrin and thrombin. At present, it is unclear as to whether the presence of vascular disruption alters the clinical course of ALS cases. A possible limitation of any study of human spinal cord tissues is the post-mortem sampling, with results reflecting an end-stage process. Thus, experimental models are needed to better characterize ALS-associated vascular dysfunction and determine whether exacerbating or mitigating the BSCB breakdown and erythrocyte extravasation in accepted experimental models of ALS contributes to motor neuron injury and disease progression during ALS pathogenesis. Sensitive biomarkers should be investigated that detect ALS pericyte reductions and capillary leakage present in spinal cord tissues. Larger studies and continued development of technologies to detect spinal cord microvascular changes hold considerable promise in deducing whether vascular disruption may represent an important variant of ALS and guide therapeutic development accordingly.

Acknowledgments This research was supported by the ALS Association grant 1859 and AG039452 to B.V.Z.

Conflict of interest The authors declare no conflicts of interest.

Open Access This article is distributed under the terms of the Creative Commons Attribution License which permits any use, distribution, and reproduction in any medium, provided the original author(s) and the source are credited.

\section{References}

1. Andersen PM, Al-Chalabi A (2011) Clinical genetics of amyotrophic lateral sclerosis: what do we really know? Nat Rev Neurol 7(11):603-615. doi:10.1038/nrneurol.2011.150

2. Annunziata P, Volpi N (1985) High levels of C3c in the cerebrospinal fluid from amyotrophic lateral sclerosis patients. Acta Neurol Scand 72(1):61-64

3. Apostolski S, Nikolic J, Bugarski-Prokopljevic C, Miletic V, Pavlovic S, Filipovic S (1991) Serum and CSF immunological findings in ALS. Acta Neurol Scand 83(2):96-98

4. Armulik A, Genove G, Mae M, Nisancioglu MH, Wallgard E, Niaudet C, He L, Norlin J, Lindblom P, Strittmatter K, Johansson BR, Betsholtz C (2010) Pericytes regulate the blood-brain barrier. Nature 468(7323):557-561. doi:10.1038/nature09522

5. Beers DR, Henkel JS, Xiao Q, Zhao W, Wang J, Yen AA, Siklos L, McKercher SR, Appel SH (2006) Wild-type microglia extend survival in PU.1 knockout mice with familial amyotrophic lateral sclerosis. Proc Natl Acad Sci USA 103(43):16021-16026. doi: 10.1073/pnas.0607423103

6. Bell RD, Winkler EA, Sagare AP, Singh I, LaRue B, Deane R, Zlokovic BV (2010) Pericytes control key neurovascular functions and neuronal phenotype in the adult brain and during brain aging. Neuron 68(3):409-427. doi:10.1016/j.neuron.2010.09.043

7. Bell RD, Winkler EA, Singh I, Sagare AP, Deane R, Wu Z, Holtzman DM, Betsholtz C, Armulik A, Sallstrom J, Berk BC,
Zlokovic BV (2012) Apolipoprotein E controls cerebrovascular integrity via cyclophilin A. Nature 485(7399):512-516. doi: 10.1038/nature11087

8. Beuche W, Yushchenko M, Mader M, Maliszewska M, Felgenhauer K, Weber F (2000) Matrix metalloproteinase-9 is elevated in serum of patients with amyotrophic lateral sclerosis. NeuroReport 11(16):3419-3422

9. Boillee S, Yamanaka K, Lobsiger CS, Copeland NG, Jenkins NA, Kassiotis G, Kollias G, Cleveland DW (2006) Onset and progression in inherited ALS determined by motor neurons and microglia. Science 312(5778):1389-1392. doi:10.1126/science.1123511

10. Brettschneider J, Petzold A, Sussmuth SD, Ludolph AC, Tumani $\mathrm{H}$ (2006) Axonal damage markers in cerebrospinal fluid are increased in ALS. Neurology 66(6):852-856. doi:10.1212/01. wnl.0000203120.85850.54

11. Chen SY, Wang Y, Telen MJ, Chi JT (2008) The genomic analysis of erythrocyte microRNA expression in sickle cell diseases. PLoS ONE 3(6):e2360. doi:10.1371/journal.pone.0002360

12. Clement AM, Nguyen MD, Roberts EA, Garcia ML, Boillee S, Rule M, McMahon AP, Doucette W, Siwek D, Ferrante RJ, Brown RH Jr, Julien JP, Goldstein LS, Cleveland DW (2003) Wild-type nonneuronal cells extend survival of SOD1 mutant motor neurons in ALS mice. Science 302(5642):113-117. doi: $10.1126 /$ science. 1086071

13. Cullen KM, Kocsi Z, Stone J (2006) Microvascular pathology in the aging human brain: evidence that senile plaques are sites of microhaemorrhages. Neurobiol Aging 27(12):1786-1796

14. Daneman R, Zhou L, Kebede AA, Barres BA (2010) Pericytes are required for blood-brain barrier integrity during embryogenesis. Nature 468(7323):562-566. doi:10.1038/nature09513

15. DeJesus-Hernandez M, Mackenzie IR, Boeve BF, Boxer AL, Baker M, Rutherford NJ, Nicholson AM, Finch NA, Flynn H, Adamson J, Kouri N, Wojtas A, Sengdy P, Hsiung GY, Karydas A, Seeley WW, Josephs KA, Coppola G, Geschwind DH, Wszolek ZK, Feldman H, Knopman DS, Petersen RC, Miller BL, Dickson DW, Boylan KB, Graff-Radford NR, Rademakers R (2011) Expanded GGGGCC hexanucleotide repeat in noncoding region of C9ORF72 causes chromosome 9p-linked FTD and ALS. Neuron 72(2):245-256. doi:10.1016/j.neuron.2011.09.011

16. Demestre M, Parkin-Smith G, Petzold A, Pullen AH (2005) The pro and the active form of matrix metalloproteinase- 9 is increased in serum of patients with amyotrophic lateral sclerosis. J Neuroimmunol 159(1-2):146-154. doi:10.1016/j.jneuroim.2004.09.015

17. Donnenfeld H, Kascsak RJ, Bartfeld H (1984) Deposits of IgG and $\mathrm{C} 3$ in the spinal cord and motor cortex of ALS patients. J Neuroimmunol 6(1):51-57

18. Dunckley T, Huentelman MJ, Craig DW, Pearson JV, Szelinger S, Joshipura K, Halperin RF, Stamper C, Jensen KR, Letizia D, Hesterlee SE, Pestronk A, Levine T, Bertorini T, Graves MC, Mozaffar T, Jackson CE, Bosch P, McVey A, Dick A, Barohn R, Lomen-Hoerth C, Rosenfeld J, O'Connor DT, Zhang K, Crook R, Ryberg H, Hutton M, Katz J, Simpson EP, Mitsumoto H, Bowser R, Miller RG, Appel SH, Stephan DA (2007) Whole-genome analysis of sporadic amyotrophic lateral sclerosis. N Engl J Med 357(8):775-788. doi:10.1056/NEJMoa070174

19. Ebert BL, Galili N, Tamayo P, Bosco J, Mak R, Pretz J, Tanguturi S, Ladd-Acosta C, Stone R, Golub TR, Raza A (2008) An erythroid differentiation signature predicts response to lenalidomide in myelodysplastic syndrome. PLoS Med 5(2):e35. doi: 10.1371/journal.pmed.0050035

20. Engelhardt JI, Appel SH (1990) IgG reactivity in the spinal cord and motor cortex in amyotrophic lateral sclerosis. Arch Neurol 47(11):1210-1216

21. Engelhardt JI, Tajti J, Appel SH (1993) Lymphocytic infiltrates in the spinal cord in amyotrophic lateral sclerosis. Arch Neurol 50(1):30-36 
22. Ferraiuolo L, Kirby J, Grierson AJ, Sendtner M, Shaw PJ (2011) Molecular pathways of motor neuron injury in amyotrophic lateral sclerosis. Nat Rev Neurol 7(11):616-630. doi:10.1038/ nrneurol.2011.152

23. Gaasch JA, Lockman PR, Geldenhuys WJ, Allen DD, Van der Schyf CJ (2007) Brain iron toxicity: differential responses of astrocytes, neurons, and endothelial cells. Neurochem Res 32(7):1196-1208. doi:10.1007/s11064-007-9290-4

24. Garbuzova-Davis S, Haller E, Saporta S, Kolomey I, Nicosia SV, Sanberg PR (2007) Ultrastructure of blood-brain barrier and blood-spinal cord barrier in SOD1 mice modeling ALS. Brain Res 1157:126-137. doi:10.1016/j.brainres.2007.04.044

25. Garbuzova-Davis S, Rodrigues MC, Hernandez-Ontiveros DG, Louis MK, Willing AE, Borlongan CV, Sanberg PR (2011) Amyotrophic lateral sclerosis: a neurovascular disease. Brain Res 1398:113-125. doi:10.1016/j.brainres.2011.04.049

26. Garbuzova-Davis S, Saporta S, Haller E, Kolomey I, Bennett SP, Potter H, Sanberg PR (2007) Evidence of compromised bloodspinal cord barrier in early and late symptomatic SOD1 mice modeling ALS. PLoS ONE 2(11):e1205. doi:10.1371/journal. pone.0001205

27. Greenberg SM, Nandigam RN, Delgado P, Betensky RA, Rosand J, Viswanathan A, Frosch MP, Smith EE (2009) Microbleeds versus macrobleeds: evidence for distinct entities. Stroke 40(7):2382-2386. doi:10.1161/STROKEAHA.109.548974

28. Greenberg SM, Vernooij MW, Cordonnier C, Viswanathan A, Al-Shahi Salman R, Warach S, Launer LJ, Van Buchem MA, Breteler MM (2009) Cerebral microbleeds: a guide to detection and interpretation. Lancet Neurol 8(2):165-174. doi:10.1016/ S1474-4422(09)70013-4

29. Guiloff RJ, McGregor B, Thompson E, Blackwood W, Paul E (1980) Motor neurone disease with elevated cerebrospinal fluid protein. J Neurol Neurosurg Psychiatry 43(5):390-396

30. Haidet-Phillips AM, Hester ME, Miranda CJ, Meyer K, Braun L, Frakes A, Song S, Likhite S, Murtha MJ, Foust KD, Rao M, Eagle A, Kammesheidt A, Christensen A, Mendell JR, Burghes AH, Kaspar BK (2011) Astrocytes from familial and sporadic ALS patients are toxic to motor neurons. Nat Biotechnol 29(9):824-828. doi:10.1038/nbt.1957

31. Henkel JS, Beers DR, Wen S, Bowser R, Appel SH (2009) Decreased mRNA expression of tight junction proteins in lumbar spinal cords of patients with ALS. Neurology 72(18):1614-1616. doi:10.1212/WNL.0b013e3181a41228

32. Henkel JS, Engelhardt JI, Siklos L, Simpson EP, Kim SH, Pan T, Goodman JC, Siddique T, Beers DR, Appel SH (2004) Presence of dendritic cells, MCP-1, and activated microglia/macrophages in amyotrophic lateral sclerosis spinal cord tissue. Ann Neurol 55(2):221-235. doi:10.1002/ana.10805

33. Hua Y, Keep RF, Hoff JT, Xi G (2007) Brain injury after intracerebral hemorrhage: the role of thrombin and iron. Stroke 38(2 Suppl):759-762. doi:10.1161/01.STR.0000247868.97078. 10

34. Ilieva H, Polymenidou M, Cleveland DW (2009) Non-cell autonomous toxicity in neurodegenerative disorders: ALS and beyond. J Cell Biol 187(6):761-772. doi:10.1083/jcb.200908164

35. Imon Y, Yamaguchi S, Yamamura Y, Tsuji S, Kajima T, Ito K, Nakamura S (1995) Low intensity areas observed on T2-weighted magnetic resonance imaging of the cerebral cortex in various neurological diseases. J Neurol Sci 134(Suppl):27-32

36. Kasarskis EJ, Tandon L, Lovell MA, Ehmann WD (1995) Aluminum, calcium, and iron in the spinal cord of patients with sporadic amyotrophic lateral sclerosis using laser microprobe mass spectroscopy: a preliminary study. J Neurol Sci 130(2): 203-208

37. Kiernan MC, Vucic S, Cheah BC, Turner MR, Eisen A, Hardiman O, Burrell JR, Zoing MC (2011) Amyotrophic lateral sclerosis. Lancet 377(9769):942-955. doi:10.1016/S0140-6736 (10)61156-7

38. Kwan JY, Jeong SY, Van Gelderen P, Deng HX, Quezado MM, Danielian LE, Butman JA, Chen L, Bayat E, Russell J, Siddique T, Duyn JH, Rouault TA, Floeter MK (2012) Iron accumulation in deep cortical layers accounts for MRI signal abnormalities in ALS: correlating 7 Tesla MRI and pathology. PLoS ONE 7(4):e35241. doi:10.1371/journal.pone.0035241

39. Lauer A, Cianchetti FA, Van Cott EM, Schlunk F, Schulz E, Pfeilschifter W, Steinmetz H, Schaffer CB, Lo EH, Foerch C (2011) Anticoagulation with the oral direct thrombin inhibitor dabigatran does not enlarge hematoma volume in experimental intracerebral hemorrhage. Circulation 124(15):1654-1662

40. Leonardi A, Abbruzzese G, Arata L, Cocito L, Vische M (1984) Cerebrospinal fluid (CSF) findings in amyotrophic lateral sclerosis. J Neurol 231(2):75-78

41. Lim GP, Backstrom JR, Cullen MJ, Miller CA, Atkinson RD, Tokes ZA (1996) Matrix metalloproteinases in the neocortex and spinal cord of amyotrophic lateral sclerosis patients. J Neurochem 67(1):251-259

42. Lindahl P, Johansson BR, Leveen P, Betsholtz C (1997) Pericyte loss and microaneurysm formation in PDGF-B-deficient mice. Science 277(5323):242-245

43. Logroscino G, Traynor BJ, Hardiman O, Chio A, Mitchell D, Swingler RJ, Millul A, Benn E, Beghi E (2010) Incidence of amyotrophic lateral sclerosis in Europe. J Neurol Neurosurg Psychiatry 81(4):385-390. doi:10.1136/jnnp.2009.183525

44. Mann GE, Zlokovic BV, Yudilevich DL (1985) Evidence for a lactate transport system in the sarcolemmal membrane of the perfused rabbit heart: kinetics of unidirectional influx, carrier specificity and effects of glucagon. Biochim Biophys Acta $819(2): 241-248$

45. Meucci G, Rossi G, Bettini R, Montanaro D, Gironelli L, Voci L, Bianchi F (1993) Laser nephelometric evaluation of albumin, IgG and alpha 2-macroglobulin: applications to the study of alterations of the blood-brain barrier. J Neurol Sci 118(1):73-78

46. Miyazaki K, Ohta Y, Nagai M, Morimoto N, Kurata T, Takehisa Y, Ikeda Y, Matsuura T, Abe K (2011) Disruption of neurovascular unit prior to motor neuron degeneration in amyotrophic lateral sclerosis. J Neurosci Res 89(5):718-728. doi:10.1002/jnr.22594

47. Moutouh-de Parseval LA, Verhelle D, Glezer E, Jensen-Pergakes K, Ferguson GD, Corral LG, Morris CL, Muller G, Brady H, Chan K (2008) Pomalidomide and lenalidomide regulate erythropoiesis and fetal hemoglobin production in human $\mathrm{CD} 34+$ cells. J Clin Invest 118(1):248-258. doi:10.1172/JCI32322

48. Nicaise C, Mitrecic D, Demetter P, De Decker R, Authelet M, Boom A, Pochet R (2009) Impaired blood-brain and bloodspinal cord barriers in mutant SOD1-linked ALS rat. Brain Res 1301:152-162. doi:10.1016/j.brainres.2009.09.018

49. Niebroj-Dobosz I, Janik P, Sokolowska B, Kwiecinski H (2010) Matrix metalloproteinases and their tissue inhibitors in serum and cerebrospinal fluid of patients with amyotrophic lateral sclerosis. Eur J Neurol 17(2):226-231. doi:10.1111/j.1468-1331.2009. 02775.x

50. Oba H, Araki T, Ohtomo K, Monzawa S, Uchiyama G, Koizumi K, Nogata Y, Kachi K, Shiozawa Z, Kobayashi M (1993) Amyotrophic lateral sclerosis: T2 shortening in motor cortex at MR imaging. Radiology 189(3):843-846

51. Pavlik A, Mares V (1992) Spontaneous hemorrhage in the cerebral cortex of immature rats. Neurosci Lett 141(2):177-180

52. Philips T, Robberecht W (2011) Neuroinflammation in amyotrophic lateral sclerosis: role of glial activation in motor neuron disease. Lancet Neurol 10(3):253-263. doi:10.1016/S1474-4422 (11)70015-1

53. Pirttila T, Vanhatalo S, Turpeinen U, Riikonen R (2004) Cerebrospinal fluid insulin-like growth factor-1, insulin growth factor 
binding protein-2 or nitric oxide are not increased in MS or ALS. Acta Neurol Scand 109(5):337-341. doi:10.1111/j.1600-0404. 2004.00223.x

54. Regan RF, Guo Y (1998) Toxic effect of hemoglobin on spinal cord neurons in culture. J Neurotrauma 15(8):645-653

55. Renton AE, Majounie E, Waite A, Simon-Sanchez J, Rollinson S, Gibbs JR, Schymick JC, Laaksovirta H, van Swieten JC, Myllykangas L, Kalimo H, Paetau A, Abramzon Y, Remes AM, Kaganovich A, Scholz SW, Duckworth J, Ding J, Harmer DW, Hernandez DG, Johnson JO, Mok K, Ryten M, Trabzuni D, Guerreiro RJ, Orrell RW, Neal J, Murray A, Pearson J, Jansen IE, Sondervan D, Seelaar H, Blake D, Young K, Halliwell N, Callister JB, Toulson G, Richardson A, Gerhard A, Snowden J, Mann D, Neary D, Nalls MA, Peuralinna T, Jansson L, Isoviita VM, Kaivorinne AL, Holtta-Vuori M, Ikonen E, Sulkava R, Benatar M, Wuu J, Chio A, Restagno G, Borghero G, Sabatelli M, Heckerman D, Rogaeva E, Zinman L, Rothstein JD, Sendtner M, Drepper C, Eichler EE, Alkan C, Abdullaev Z, Pack SD, Dutra A, Pak E, Hardy J, Singleton A, Williams NM, Heutink P, Pickering-Brown S, Morris HR, Tienari PJ, Traynor BJ (2011) A hexanucleotide repeat expansion in C9ORF72 is the cause of chromosome 9p21-linked ALS-FTD. Neuron 72(2):257-268. doi: 10.1016/j.neuron.2011.09.010

56. Rosidi NL, Zhou J, Pattanaik S, Wang P, Jin W, Brophy M, Olbricht WL, Nishimura N, Schaffer CB (2011) Cortical microhemorrhages cause local inflammation but do not trigger widespread dendrite degeneration. PLoS ONE 6(10):e26612. doi: 10.1371/journal.pone.0026612

57. Schliep G, Felgenhauer K (1978) Serum-CSF protein gradients, the blood-GSF barrier and the local immune response. J Neurol 218(2):77-96

58. Troost D, Van den Oord JJ, Vianney de Jong JM (1990) Immunohistochemical characterization of the inflammatory infiltrate in amyotrophic lateral sclerosis. Neuropathol Appl Neurobiol 16(5):401-410

59. Verstraete E, Biessels GJ, van Den Heuvel MP, Visser F, Luijten PR, van Den Berg LH (2010) No evidence of microbleeds in ALS patients at 7 Tesla MRI. Amyotroph Lateral Scler 11(6):555-557. doi:10.3109/17482968.2010.513053

60. Werring DJ (2011) Cerebral microbleeds. Cambridge University Press, London

61. Winkler EA, Bell RD, Zlokovic BV (2010) Pericyte-specific expression of PDGF beta receptor in mouse models with normal and deficient PDGF beta receptor signaling. Mol Neurodegener 5:32. doi:10.1186/1750-1326-5-32

62. Winkler EA, Bell RD, Zlokovic BV (2011) Central nervous system pericytes in health and disease. Nat Neurosci 14(11): 1398-1405. doi:10.1038/nn.2946

63. Winkler EA, Sengillo JD, Bell RD, Wang J, Zlokovic BV (2012) Blood-spinal cord barrier pericyte reductions contribute to increased capillary permeability. J Cereb Blood Flow Metab. doi: $10.1038 / \mathrm{jcbfm} .2012 .113$

64. Xi G, Keep RF, Hoff JT (2006) Mechanisms of brain injury after intracerebral haemorrhage. Lancet Neurol 5(1):53-63. doi:10. 1016/S1474-4422(05)70283-0

65. Yamanaka K, Chun SJ, Boillee S, Fujimori-Tonou N, Yamashita H, Gutmann DH, Takahashi R, Misawa H, Cleveland DW (2008) Astrocytes as determinants of disease progression in inherited amyotrophic lateral sclerosis. Nat Neurosci 11(3):251-253. doi: $10.1038 / \mathrm{nn} 2047$

66. Zhong Z, Deane R, Ali Z, Parisi M, Shapovalov Y, O’Banion MK, Stojanovic K, Sagare A, Boillee S, Cleveland DW, Zlokovic BV (2008) ALS-causing SOD1 mutants generate vascular changes prior to motor neuron degeneration. Nat Neurosci 11(4): 420-422. doi:10.1038/nn2073

67. Zhong Z, Ilieva H, Hallagan L, Bell R, Singh I, Paquette N, Thiyagarajan M, Deane R, Fernandez JA, Lane S, Zlokovic AB, Liu T, Griffin JH, Chow N, Castellino FJ, Stojanovic K, Cleveland DW, Zlokovic BV (2009) Activated protein C therapy slows ALS-like disease in mice by transcriptionally inhibiting SOD1 in motor neurons and microglia cells. J Clin Invest 119(11):34373449. doi:10.1172/JCI38476

68. Zhong Z, Winkler EA, Zlokovic BV (2011) Microhemorrhages: undetectable but clinically meaningful the question persists. Amyotroph Lateral Scler 12(3):231-232 (author reply 233-234). doi: $10.3109 / 17482968.2011 .565776$

69. Zinman L, Cudkowicz M (2011) Emerging targets and treatments in amyotrophic lateral sclerosis. Lancet Neurol 10(5):481-490. doi:10.1016/S1474-4422(11)70024-2

70. Zlokovic BV (2011) Neurovascular pathways to neurodegeneration in Alzheimer's disease and other disorders. Nat Rev Neurosci 12(12):723-738. doi:10.1038/nrn3114

71. Zlokovic BV, Apuzzo ML (1997) Cellular and molecular neurosurgery: pathways from concept to reality-part I: target disorders and concept approaches to gene therapy of the central nervous system. Neurosurgery 40(4):789-803 (discussion 803-784) 